\title{
How to characterize research and scholarship that matters for the educational field?
}

European Educational Research Journal $1-14$

(C) The Author(s) 2019 Article reuse guidelines: sagepub.com/journals-permissions DOI: | 0.1 | 77/|474904 | | 9865857 journals.sagepub.com/home/eer

(S)AGE

\author{
Paul Smeyers \\ Faculty of Psychology and Educational Sciences, Ghent University, Belgium; Faculty of Psychology and Educational \\ Sciences, KU Leuven, Belgium
}

\begin{abstract}
For many decades, debates about the 'what' and 'how' have haunted the academic discipline of education. The temptation to rely on methods characteristic of empirical educational research can also be observed in some developments of philosophy of education. Both stances are criticized for neglecting various aspects in their approach as well as in the content studied: the field of education and child-rearing. Starting from the crystalline purity that may be looked for either in content or method, it is argued the research and scholarship that matter for the educational field should envisage research and reflection that attends sensitively and practically to both the particular and the general dimensions of that which one is examining. This requires a pragmatic concept of interpretation, a way of characterizing philosophy that focuses not only on the overview it may offer, and a balance between all the elements at stake. Only thus may it be possible to ask the right questions and to take up personal ownership of one's own ethical and practical stance towards the people, things and phenomena one is researching, an invitation to find one's own place within the world, helping us to make sense of life and to act responsibly.
\end{abstract}

\section{Keywords}

Method, overview, Wittgenstein, interpretation, educational research, philosophy of education

\section{The scope of the discipline}

Philosophy of education offers a wide variety of ways to bring together different philosophical stances and ideas about education and child-rearing. It is tempting to fall into the trap of legislating what this sub-discipline ought to tackle, yet such attempts, sophisticated as they have been, have not proven successful in the past. Philosophers have always transgressed the boundaries of their discipline set by their predecessors and education and child-rearing have developed in unforeseen

\section{Corresponding author:}

Paul Smeyers, Faculty of Psychology and Educational Sciences, KU Leuven, 3000, Belgium.

Email: paul.smeyers@ped.kuleuven.be 
ways, necessitating further work on the meanings of these terms and what is at stake in our understanding of them. Many issues have been discussed: for example, in what sense is philosophy different from literature and if there is a difference, then what is to count as literature? Is education a kind of political action and, if so, what is to be understood by 'political'?

Similarly, empirical educational research, which mostly starts from a particular problem that educational practitioners experience (either in classrooms or in educational settings, or as a parent or social worker) looks for solutions, makes comments, or directs people to issues that have not been dealt with. There are all kinds of issues that arise. It concerns dealings between parents and children, teachers and pupils and further educational policy. Given this wide variety of interest, one can pursue all kinds of methods in the context of educational research.

There are good reasons for taking the view that education and child-rearing are practices ${ }^{1}$ and so are their philosophical counterparts. Philosophy seems to supply the central arguments for this view, thus exposing the embeddedness of any one point of view in more far-reaching sets of assumptions. Thus, it can enable us better to understand what might be at stake in any particular viewpoint and to come to a conclusion for which there is discernible, appropriate warrant, albeit one that is always exposed to critique. But the nature and force of such arguments bear witness themselves, of course, to philosophical stances. It goes without saying that in these stances epistemological, anthropological, ethical, metaphysical, religious and even aesthetical elements are interwoven in various ways, together with societal conditions. Similarly, there is a variety of conceptions of education and child-rearing that inspire practitioners and theoreticians alike. No final word on these can be offered to settle the debate forever, for the simple reason that such practices change due to a huge range of social and material circumstances, leading, for example, to different manners of teaching or new types of families. The influence of all these changes on practices of education and child-rearing can therefore hardly be underestimated. Combined with different conceptions of the task of philosophy, this has generated a vast array of writing in recent years where varying content is discussed from diverse positions.

Looking for crystalline purity in the analysis of these changes is a sure recipe for disappointment. ${ }^{2}$ What we are looking for, some would say, are 'houses of cards'. To change the metaphor, to try to go beyond the multifariousness of language and meaning leaves us with nothing more than 'an engine idling'.

We want to establish an order in our knowledge of the use of language; an order with a particular end in view; one out of many possible orders; not the order. To this end we shall constantly be giving prominence to distinctions which our ordinary forms of language easily make us overlook. (Wittgenstein, 1953, I: § 132)

For Wittgenstein, the work of the philosopher is characterized by 'assembling reminders for a particular purpose' (Wittgenstein, 1953, I: $\S 127$ ). Surely philosophy is about arguments, but what is an argument? It is about meaning, knowledge, values, being human, the good, the beautiful, etc., but none of these can easily be delineated without building on other insights. That is how everything hangs together, has meaning for us: a particular order is made explicit and although this is for me and others the order that appeals most, it should be realized that this is only one out of the many possible orders that can be argued for.

Child-rearing and education too will not fare well either with a 'clear' - in the sense of 'crystalline' - picture. It is often forgotten but true nevertheless that there are many roads to Rome, and not everyone wants to go to Rome anyway. There may be roads that should be avoided, some may be better, others may pose problems, yet such cases always need to be made with attention to general dimensions and to particulars, warranting detailed argumentative content and structure. Educators 
are pressed to take action, to 'do' certain things; they want to create certain opportunities; however, they are often unsure not only about the 'how to'; they care deeply for those they are entrusted with and desperately try to avoid mistakes. They too often want to believe there is only one way (or one that is the very best). The emotional disturbance this situation creates and the dilemmas to which one may be exposed make it understandable that the justification they offer for their choices may be worded more strongly than the nature of these matters allows. The illusion of absolute control looms at the horizon, even if one realizes it is neither possible nor desirable. After all, one feels responsible; at the same time one can neither anticipate all the dangers and risks nor the opportunities involved in leading a human life.

Turning to reflection and research helps, but it cannot do away with the constraints and tensions in which one finds oneself. Surely there is joy in bringing things together, in making sense of them, but there always remains pain in the realization of what has been left out, and yet still we need to act. This points to the need to be modest about what can be achieved through philosophical reflection, in any particular case, both for the individual person and for society at large. Addressing, for example, the surveillance society and its implications for privacy issues and the wellbeing of citizens, it should be realized that it is one thing to make this explicit, yet another to turn the clock back or to deal with the problem appropriately. This is not to say there is no place for such a debate, but it is quite another thing to expect from foregrounding what is involved that things will change accordingly and rapidly; however, it goes without saying that such reflection may have the capacity to inspire. In sum, there may not be final answers but there certainly are answers worth looking at, in particular when these offer balanced insights, critically appraised, not overstepping the boundaries of what may be achieved yet not avoiding responsibility for what is argued for, possibly radical yet not one-sided. . . aspiring to offer a kind of wisdom. For some what has been characterized above is not enough. They long for strict boundaries and they want to rely on method, for empirical educational research as well as for philosophy of education. A clear example of this is the appeal for evidence-based educational research, in particular, the form this has recently taken (see further where scientism is discussed). An illustration of the almost uncritical reliance on the empirical educational approach and where this may lead us is, for instance, the educational neuroscience or neuroeducation hype. Hardly any attention is given to the many problems that this approach poses, such as the assumption that 'visual proof' of brain activity is given; the correlational nature of this kind of research; the nature of the concepts that are used; the lack of addressing and possibly influencing the neurological mechanism; and finally the need to incorporate other insights of the educational context. ${ }^{3}$

\section{The temptation to rely on 'method' in educational research}

Educational research is different from a discipline such as archaeology, where one studies something just to understand it. Although there are some issues in educational research like that (pursued for a theoretical interest and only for that theoretical interest), most educational issues start from problems that you are presented with in educational settings. Educational research and educational theory are also different from sciences such as physics or chemistry - even from experimental psychology - in the sense that there you look for an answer to a specific problem in terms of the independent variable that you can manipulate to have a particular result in terms of your dependent variables. ${ }^{4}$ I do not think a particular idea of a theory is the kind of theory that educational research should embrace. Educational research is more like deepening understanding about particular issues, not about establishing things once and for all. Instead what is dealt with and reflected on is the particular situation we live in, the historical context, the variety of things people find important in that particular context and so on. To these, one could say, one holds a mirror; it makes us more aware of all the issues involved. From there a lot of things follow for practice, but 
they do not follow in the sense that you can anticipate all minuscule kinds of things to have a certain outcome. That is not how education works, and so we need a different kind of theory. Some would say there is no theory in the traditional sense of the word because there is no hypothesis that can really be tested. So, you bring ethical considerations, you bring ideas about what the human being is, about how society should be and so on; all these come together. They do not fall under the traditional notion of the umbrella concept of a theory that can be tested as such. Different from an educational practitioner (a teacher, a parent) the educational researcher has the freedom to stand back and to reflect and to identify what at least some of the presuppositions of a particular action are and what the pros and cons are of that, and what the other presuppositions for other actions are, and so on. This reflection may help the practitioners to make up their mind.

I am keen to caution against any false hope that the phenomena and problems that are of interest to educational researchers might easily yield to such causal relations as are captured in laws of nature expressed in terms of independent and dependent variables. Educational research is distinctive, because its engagement with its subject matter is more than merely of theoretical interest. Educational research concerns itself with a call to respond practically to an issue or problem that emerges from a particular educational context: schooling, parent-child relations and so on; and especially when such calls appear otherwise neglected or overlooked. This, of course, is not to deny the possibility of scientific methods being used in the service of educational research; rather, it is to suggest that many different approaches may be applied to educational problems and therefore we ought to be discerning when matching these methods to what is called for by the problems and issues at hand. I want to point in the direction of doing research that attends sensitively and practically to both the particular (the specificity of the problem one is dealing with) and the general dimensions of that which one is examining (the broader landscape that makes it meaningful). Nowadays, the climate of contemporary research and its dominant modes of scholarship is making such a perspectival balance increasingly intractable. The dominant culture of performativity in which metrics have irrevocably transformed what counts as academic success, the fast-paced channels of communication, the drive for novelty and the increased degree of specialization amongst academics is especially antithetical to research of this balanced kind. Instead, we should, as Aristotle invites us to, orient ourselves towards research that is at once the enactment and the pursuit of wisdom. Research in education cannot rely on strictly scientific modes of inquiry because the kinds of problems with which education is concerned require theoretical, ethical and practical forms of wisdom. From this, a call follows to take up personal ownership of one's own ethical and practical stance towards the people, things and phenomena one is researching, an invitation to find our own place within the world, helping us make sense of life and to act responsibly.

There is a history behind the adulation of the scientific and empirical in the west, behind its 'scientism'. It should be realized, however, that whatever rules of method are stipulated, their application will still require judgement (see in particular endnote 9). And there cannot be further rules for their application or, if there are, there cannot be an endless series of such rules. The qualities that make up judgement - flexibility, attentiveness, suitable experience and so on - are found more in some people than in others. They are found, for instance, in those who have a rich acquaintance with the subject matter in hand and in those prepared to attune themselves to the subject matter rather than treat it as one more field for the operation of pre-established skills and techniques. These implications are perhaps less obvious today, but the notion that there are research methods that can be acquired relatively straightforwardly by almost any aspiring researcher, irrespective of their general intellectual sophistication, quality of judgement and understanding of the subject being researched, is nevertheless prevalent. ${ }^{5}$ A number of textbooks offer their readers knowledge of research techniques: chapters on ethnomethodology, participant observation, interviewing, discourse analysis, grounded theory and a plethora of 'isms'. Courses on research methods leave 
students under the impression they can write a dissertation on 'whether the National Curriculum is improving children's reading skills'; they are upset when it is suggested that hard thinking needs to be done about just what counts as reading and whether it consists of skills. The point is not that ethnomethodology, participant observation and the rest are without value: of course, they have their uses and many classic pieces of educational and social science research have employed them to good effect. The problem is where they stand in for the cultivation of judgement and insight, and for acquaintance with the broader background of ideas and theory; where emphasis on the acquisition of such techniques even distracts from such cultivation and acquaintance and diminishes the time available for them.

An example of this would be the often-made claim that all knowledge - or all true knowledge, perhaps - arises in the context of problems to be solved. The implications of this argument, if it could be sustained, would be considerable: it could be used to support curriculum reform in the direction of discovery learning, or something very like it, and it would be a valuable weapon in the battle that its proponents like to think they as waging against didacticism or the assumption that teaching consists of pouring facts into empty heads. There are cases where it is about problem solving, there are other cases, however, that are very different where it is important to realize other issues have to be taken into account, and these you have to be familiar with. There is a trivial sense in which perhaps all learning can be called problem solving, which is not the same and a more substantial sense as when you wish you had learned more. This is the source of the idea that some embrace: courses in educational 'research methods' that proceed as if students largely lacking in 'wits' or 'individual excellence' can be suitably equipped to go out (into the 'real world', naturally) and conduct empirical research into anything indifferently. The effect of this background is that science has come to seem the only game in town. In short, the word 'science' and its derivatives have rhetorical force; for a great deal of the time they are used rhetorically, that is to persuade by the suggestive power of words rather than by rational argument. The neglect of the distinctive conception of the Geisteswissenschaften is unfortunate because out of it there emerged an emphasis on understanding the meaning (Verstehen) of human behaviour as opposed to seeking an explanation (Erklärung) of it. This distinction is extremely important in what we call the social sciences and we often find ourselves in intellectual trouble if we forget it. The conclusions researchers arrive at are likely to be tentative and provisional rather than definitive. The very process here may well have an important influence on their understanding of themselves and their world and on their future patterns of behaviour. All of this is very different from the scientific examination of physical matter and from scientific explanation. In the face of the ever-increasing expectation that social scientists should copy the methods of physical scientists, it is necessary continually to recall and insist on the importance of this verstehen element of social science and what this entails for interpretation. ${ }^{6}$

\section{Interpretation in the discipline of education ${ }^{7}$}

Interpretation is central to all kinds of educational research and enters it at every stage of the process. The selection of the focus of inquiry depends on a certain reading, an interpretation, of the arena of policy and practice and of the existing research and other literature as well as of the interests of the researcher. The formulation of a research question or questions draws upon conceptual and value assumptions that frame a particular version or interpretation of the world. The selection of a mode or method of enquiry, of sites for the research, of participants, and of the forms of data or other resources to be assembled depends on an understanding, an interpretation, of the nature of the matter to be investigated and of the kinds of conclusions that different forms of enquiry can be expected to yield. Some of the data assembled will be constituted by participants' interpretations of events and experiences - their responses to new educational programmes or teaching styles, 
their life histories, their understandings of policy requirements etc. The processes of organizing data, identifying what is important and worth paying attention to, selecting what will be reported and trying to make sense of it all through some appropriate form of analysis or argument, all entail interpretive judgements. The write-up of research results and choices about the forms and media for representing those results, requires interpretation. And finally, the uses made of research: the conclusions drawn for policy, practice and the formulation of further research questions are all interpretive at their heart. These conclusions are themselves the product of interpretations not only of the research but of the place of research within wider educational theories.

Educational research is not simply a social science or one of the humanities. Rather, it is a field of study that draws on a range of disciplines including social sciences and humanities, while itself remaining distinguishable from any of them. Interpretative frameworks are thus brought to a piece of research, embodied in the data and resources we assemble through research, generated out of interaction between the theoretical frameworks that the researcher brings to the research and all that they encounter through the research process and reflected in the kinds of writing and publication of outcomes, given the particular audience for which they are intended. Educational research is often carried out to make a difference or an improvement within educational settings, so researchers are necessarily required to interpret how that might best be achieved. Interpretation is not a method in itself, but a characteristic of any research method - indeed of the research process itself. These arguments pertain to research in every domain, from the social to the natural sciences, from the humanities to astrophysics.

This pragmatic approach emphasizes that human needs and purposes differ in the doing of research and although rigour and accuracy matter, there is no single approach that always offers the kinds of rigour and accuracy needed - sometimes a large sweeping account is more useful and at other times too general and not contextually specific enough; sometimes, similarly, an intense study of particulars may provide rich contextual understandings, but require a different, perhaps 'naturalistic', kind of generalizability that those more accustomed to statistical probabilities might find uncomfortable. Focusing on these questions of purpose should help to tone down the often highly charged, partisan and blinkered way in which different theoretical and research traditions characterize one another. Another aspect of this pragmatic approach is to focus on what researchers do when they are doing research. Rigour and accuracy come not from choosing one method over another, but from applying an appropriate method carefully, with integrity, skill and experience. Thus the word 'discipline' is used to describe fields of investigation for a reason: methods and traditions of inquiry, a body of literature and a scholarly community of peers supporting and providing structure to the discipline of inquiry for any individual scholar. One of the crucial dimensions of this discipline is the reflective self-awareness of the role of interpretation and judgement in the processes of inquiry.

All research traditions acknowledge that researchers do not embark on their research as blanks whose ideas and understandings are shaped exclusively by the data they collect, unaffected by any previous experience or presuppositions. Indeed, it is a good thing that researchers bring all sorts of experience, scholarship, rigorous training and theoretical and practical understandings to their research. But with all this they bring pre-formed, pre-established 'horizons', as Gadamer might refer to them, pre-existing interpretive frameworks and these very same horizons can become impediments, biases, or blind spots. Different research traditions have, of course, different ways of dealing with such interpretive frameworks. In the traditions of the natural sciences and in those social science traditions that aspire to the condition of the natural sciences, the presence of the researcher and all their pre-existing understandings, expectations and interpretive frameworks can be viewed as potentially biasing the research. In these contexts, the aim is as far as possible to neutralize any such biases. Thus, the research genre requires, for example, experimental controls 
that neutralize the presence of the researcher and any influence they might exercise on the events being studied. In cases where the observer changes the situation simply by observing (as in many areas of natural science), an attempt is usually made to eliminate the effect of any specific individual observer, as opposed to a generalized observer. Researchers working within some other genres of research acknowledge the inevitability of such presuppositions and personal commitments and do not seek to neutralize them. However, they attempt to minimise the effects of individual subjectivities through a scrupulous exercise of personal reflection and self-scrutiny, rendering possible a kind of distance and objectivity. How a person conducts an interview, for example, and tries to identify with comments or values quite different from their own, or tries to give fair credence to positions they personally disagree with, are all indicators of an attempt to acknowledge one's own horizons but avoid being trapped by them. These researchers take the view that the subjectivity of the researcher is both a help and a hindrance.

Yet other genres of research are predicated on the view that such attempts to eliminate or avoid such pre-understandings are in principle doomed to failure and so prefer instead to have them acknowledged and disclosed explicitly. Sometimes this involves laying out a series of theoretical assumptions and categories guiding the research study. Sometimes it takes the form of a 'biographical positioning' of the researcher vis-a-vis the research topic or research subjects. Sometimes it involves comments of a more personal nature, disclosing the investment and commitments a researcher brings to an investigation. Whatever form it takes, an open and honest acknowledgement of the researcher's interests, commitments, background and assumptions can enable the reader to take account of such positioning or perspective in their own reading and interpretation of what is presented. On this account, it is the failure to acknowledge the presence of a specific researcher that leads to bias.

Another way in which researchers bring their understanding to educational research has to do with the values inherent within education. Education cannot be understood at all in the absence of values about what is ethically and epistemologically worthwhile for an individual, or for a whole society. Hence, conducting research will have additional constraints precisely because, as was remarked earlier, the educational research is usually intended to make some kind of difference or improvement to the understandings within and conduct of educational practices and policies. Thus few educational researchers simply choose to investigate what intrigues them, instead they focus on what matters to them within education. A researcher's stance towards such frameworks will affect the way that research is conducted, affecting not only the collection of data, but also how they are analysed and the conclusions that are drawn from them.

An interpretation is a kind of argument, but the ways in which evidence is marshalled in support of that argument differ. The idea is to show the significance of something that is not immediately apparent: an interpretation often asks the audience to see things in a particular way, or from a particular vantage point. The interpretation is a kind of case that needs to be made: an effective interpretation helps the audience to see connections or implications that they did not see before. It does so in how the case is made as much as through the evidence garnered in support. Usually, an interpretation refers to something important (note that the term 'significance' here relates to both the idea of importance and the idea of meaning) - something worth attending to. This process of showing things in a particular way is distinct from the idea of getting an answer 'right' in the sense of there being one correct - and true - answer. Some interpretations have other uses, revealed by the adjectives attached to them, such as 'illuminating', 'trustworthy', 'provocative', 'political' or 'insightful'. Other kinds of interpretation may provide a range of possible 'right' answers: there may be more than one way to interpret a racist or sexist comment, for example, each one representing a different facet of understanding or point of view. Equally, there is also a range of possible 'wrong' answers. Some interpretations of complex data, such as works of art or personal narratives, 
may draw upon conceptions of truth different from the kind of conception found in a correspondence theory of truth, or a requirement to 'just stick to the facts'. For instance, they may draw upon ideas of 'individual truth' ('that is my truth, now tell me yours') or of the significance of 'truthfulness' rather than 'truth'.

As noted, the rhetoric of interpretative argument also differs. Sometimes it takes the form of a literal argument, with evidence marshalled in support of a logical inference. Sometimes it is more oblique, amassing and presenting particulars that have a cumulative effect in changing the way one understands something. Sometimes it is more invitational, suggesting, 'If you look at it this way you will see the thing differently'. Sometimes an interpretation has qualities in common with the thing being interpreted: explaining the meaning of gestures or expressions by repeating them, or by pantomiming others; explaining a poem through a style of expression that is itself poetic; casting doubt on a viewpoint using mimesis. This link between rhetoric of interpretation and the rhetoric of the things to be interpreted partly explains why the styles are so varied and irreducible to a single method. An interpretation stands between an audience and an object, mediating an understanding in the same way that a translator mediates between speakers of two different languages. This intermediary role itself entails obligations, because for many audiences the only appreciation of the object will come through the interpreter's efforts at explaining it. And so a certain honesty or integrity in the interpreter needs to be relied upon.

In many cases, it is easier to talk about the ways in which an interpretation can go wrong: it lacks fidelity to the evidence; it is repetitive, or a cliché, and adds no new understanding to the matter; it fits some particulars, but neglects aspects of the chronology of events, the context or the whole; similarly, an interpretation can be tendentious, incomplete, driven by a conclusion rather than an attempt to provide a comprehensive view; or it can be useless, irrelevant to the needs of the moment; or it can be uninteresting, boring. Just as an interpretation can be good in many ways, it can be bad in many ways. And so, matters of judgement come into the discussion; matters of need and purpose; matters of individual interests; and matters of context and circumstance. Interpretation is not only an 'essentially contested concept', it is at the essence of why there are 'essentially contested concepts'.

\section{The temptation of method in philosophy and philosophy of education}

Following developments in 'ordinary-language philosophy' in the English-speaking countries after World War Two, a particular style of philosophy of education became influential. Predominantly analytical and aiming for something more systematic than was available at the time, it sought to bring a new rigour to its subject and to replace the rather woolly version of educational theory in which the various theoretical disciplines could barely be distinguished. Along these lines philosophers of education identified and exposed fallacies in reasoning, battled against fundamental errors such as ethical relativism and epistemological reductivism and aimed for a coherent and systematic rationalization of beliefs and practices. This was to be achieved by importing the rigour and the supposed ideological neutrality of linguistic and analytic methods from philosophy more broadly. Due to a relentless pursuit of clarity and truth, philosophy of education came to be seen as epistemologically foundational: as the judge of matters of value and meaning and the arbiter of appropriate theory for explaining human behaviour in the educational sphere. The criticisms of this position raised in the half of a century since then are well known: 'truth' has now come to seem a little less innocent; analytical philosophy of education relied too much on the notion that the distinctions made in ordinary language, once recovered and clarified, have the power to sweep away the 
obscurities introduced by tendentious ways of thinking and writing; and the aspiration to map the logical geography of educational concepts was naïve in its supposition that there is such a geography, unitary and one-dimensional, to be definitively mapped. In the Blackwell Guide to the Philosophy of Education (Blake et al., 2003) it was argued that philosophical analysis may still concern itself with problems rooted in the use of language in educational discourse. Although this task is not anymore that of a conceptual underlabourer, analytic techniques remain useful. Furthermore, philosophy of education should still address the assumptions and values embedded in other disciplinary approaches to the study of education, whether these are explicitly promoted or tacitly assumed in policy and practice. Obviously, this is now a debate between philosophy and other disciplines on equal terms. Finally, it is clear that philosophy of education has to explore what education might be or might become. It can revisit but also problematize its canonical questions about matters such as the aims of education, the nature of knowledge and the point of particular curriculum subjects, about human nature and human practices.

It is recognized by practitioners and theoreticians that neither insights from philosophy of education nor those from educational theory more generally can be applied in educational contexts in any straightforward way. Yet philosophical argument may show that some questions do not make sense. The philosopher can unsettle and provoke by offering another reading, another interpretation. However, they cannot impose a compelling argument for either educational practice or theory. Others will follow this and stress that every answer is necessarily tentative. JeanFrançois Lyotard and others have argued that because of our historical 'thrownness' in the world, we are only capable of producing 'small' and thus very fragmentary stories. But we can readily live with such heterogeneity of genres and plurality of stories. Indeed, a supra- or extra-historical Archimedean point that could be grasped is not available, and whoever thinks they have found it opens the door for a revival of ideological fundamentalism and fanaticism. Only by taking the particular into account can we possibly arrive at interesting insights. At the same time, the historical dimension warns us that the concepts and frameworks we use mark and limit our interpretations. Despite the fact that we are necessarily aware of the fragmentary nature of our work, we cannot transcend its limitations.

Wittgenstein's understanding of the aim of philosophy in its most general and positive form is that it offers an Übersicht, a surview or perspicuous representation. This can only be achieved by a patient investigation of the way sentences and expression are 'applied' and of their rule-governed connections. He uses many examples, often imaginary language games, sometimes exaggerated or impossible ones, cases that, through juxtaposition with our ordinary experience, point towards the limits of intelligibility of segments of 'grammar'. Philosophy should not be involved with metaphysical propositions in an attempt to express the essence of something; there are no new facts to be discovered, only new insights on old facts. Theorization is a temptation. It carries the allure of an expertise that transcends the bounds of context and brings with it a vocabulary of 'super-concepts'. Thus in education, 'motivation', 'play', 'development', 'creativity', 'imagination', 'learning', 'aim', 'objective', 'competence', 'skill' and 'self-esteem' acquire a bogus aura of significance. Wittgenstein would bring these words back to the ordinary circumstances of their use (Wittgenstein, 1953, I: $\S 116)$. Theorization may emerge where an unclarity about the meaning of words leads to expression in the form of a scientific question. But this is, according to him, a typically metaphysical question (Wittgenstein, 1969: 35). The urge to theorize is perhaps telling, however, in that it is symptomatic of a reaching after significance, a significance that the failure to attend to particulars denies us. Thus, to recall the particular is the method for every philosophical investigation: its result is also referred to as a new way of looking at things (Wittgenstein, 1953, I: § 401). Philosophy, for Wittgenstein, is therapy: for by seeing how language actually works, philosophical problems disappear and philosophical questions come to an end. 
The real discovery is the one that makes me capable of stopping doing philosophy when I want to. The one that gives philosophy peace, so that it is no longer tormented by questions which bring itself in question. Instead, we now demonstrate a method, by examples; and the series of examples can be broken off. Problems are solved (difficulties eliminated), not a single problem.

There is not $a$ philosophical method, although there are indeed methods, such as different therapies. (Wittgenstein, 1953, I: § 133)

The aim is to teach someone to pass from a piece of disguised nonsense to something that is patent nonsense (cf. Wittgenstein, 1953, I: § 464), as the 'repressed nonsense' is made explicit. To combine freedom and restraint meaningfully, one has to stop questioning deliberately, as to seek further 'grounding' will remove the immediate connection to the facts and will end up in the interwovenness of language and the world. Confronted with the question why this is the answer, one can only say that this is how we act: 'What people accept as a justification - is shown by how they think and live' (Wittgenstein, 1953, I: $\S 325$ ). So the aim of philosophy can be said to be 'To shew the fly the way out of the fly-bottle' (Wittgenstein, 1953, I: § 309). Elsewhere he describes the result of a philosophical investigation as follows: 'I wanted to put that picture before him, and his acceptance of the picture consists in his now being inclined to regard a given case differently: that is, to compare it with this rather than that set of pictures. I have changed his way of looking at things' (Wittgenstein, 1953, I: § 144). It is 'As if you had invented a new way of painting; or, again, a new metre, or a new kind of song' (Wittgenstein, 1953, I: § 401). Wittgenstein also pointed out that giving reasons in philosophy can be compared with giving reasons in aesthetics. One may speak of a debate, but this does not lead to conclusions; rather, its function is to make those involved sensitive to the way something can be appreciated. Elsewhere he writes: 'I think I summed up my attitude to philosophy when I said: philosophy ought really to be written only as a poetic composition' (Wittgenstein, 1980: 24e).

It is important to be clear about what Wittgenstein calls a 'perspicuous representation'. This is manifestly not an exhaustive explanation; it is necessarily partial, covering a limited domain of our experience or a limited segment of grammar. The 'craving for generality' (Wittgenstein, 1969: 18), with its contemptuous attitude towards the particular case, is to be resisted and is set against any ideal of an overarching theory. It is also closely linked with the idea of seeing aspects. Wittgenstein deals with this extensively in Part II, xi of the Philosophical Investigations (1953). In the puzzle picture of the duck-rabbit (Wittgenstein, 1953, II: 194) it is not the addition of a datum that allows the alternative picture to be seen but the dawning of an aspect such that the structural role of each part of the picture is quite different. A key point here is the primacy of (non-deliberative) interpretation. What is first seen is a duck or a rabbit. It is not the case that we first 'see' the visual data and then construct from these one or the other meaningful image. It would be closer to the truth to say that it is through abstracting from the picture of the duck or the rabbit that we can identify the lines that make it up. And this move is a privative one along the lines of the procedures of science. But even through this abstraction we do not arrive at any atomism of visual data. For what is to count in our observation will itself be determined by further interpretations, as, for example, to do with the idea of a drawn line. The duck-rabbit is unusual as a reading of the drawing can go either way: normally an interpretation forces itself on us. Even a proof in mathematics is not so much a logical deduction from a series of propositions but something that we see. Not seeing a pattern will mean that we do not know where we are or how to go on; seeing it will be the result of a training not in generic skills but in correct judgements.

Stanley Cavell (in Gibson and Huemer, 2004) argues that Wittgenstein claims for the ordinary its own possibility of perspicuousness. 'Perspicuous representation is accordingly the end of a philosophical problem that has this form of beginning' (Cavell in Gibson and Huemer, 2004: 23). 
He recalls that the philosopher's treatment of a question is according to Wittgenstein like the treatment of an illness, a sickness of the understanding as well as a sickness of the will. Philosophy must learn to give itself peace, which means to break off from asking the wrong questions: it has to surrender, to entrust itself with 'how things are' in ordinary life. We have to give up our search for criteria and our disappointment that we cannot find them. The therapy Wittgenstein speaks of consists in shedding the demand for something more. A good example of this is the demand for authenticity that leads to the search for 'the real self', a chimaera for which the quest is doomed. Another is the sense that the language we inherit is inadequate, as if there might somewhere be a perfect language to 'do justice to the real world'. Hence the importance of literature: literary texts do not use language to represent anything real, in the mundane sense, but return the reader to the workings of language itself. Doing philosophy is therapeutic for that person in the sense that it changes them, undoing the knots in their understanding.

This conception of philosophy foregrounds the idea of working in such a way that achieves understanding not so much through explanation but rather through faithful description and proper attention to particulars. Recognising the constraints of particular formulations of our difficulties and the ways in which we might be released from these is not only the business of good philosophers, novelists, playwrights and other artists: it is rightfully also the work of therapists, parents, managers, colleagues and friends. There is for Wittgenstein no single method in philosophy and neither is there in education. Sometimes these methods will involve changes of aspect: to enable us to gain a clear view of a facet of learning; to enable us to understand the circumstances of an individual or of a social group; to enable us to see other possible ways of doing things, perhaps altering the horizons of our understanding of what education can be. Seeing the point of what is argued for may further be specified for instance as offering differentiations and indicating 'what has been forgotten', drawing out further implications of what is at stake, or offering additions to the research agenda. Such dissolutions and resolutions do not settle things finally but recurrently, clearing the way for engagement. These contributions will thus have to be evaluated on their own merits. Because of this, the whole notion of 'method'8 (in educational research including in philosophy of education) must be dispensed with. For it is in the nature of education that it is always to be struggled with, never comfortably settled.

Many philosophers of education have criticised the language of instrumentalism, that is of exclusively means-end reasoning, central to both quantitative and qualitative educational research. Often this critique argues that insufficient attention is given to ends themselves. The discussion of ends is therefore divorced from scientific and/or rational debate. By drawing attention to a famous regress that Lewis Carroll described, ${ }^{9}$ the position that 'all there is to practical rationality is instrumental rationality' can be criticised in a more specialized sense. Because instrumental rationality involves a higher-order commitment to combine willing an end with taking the necessary means, it therefore cannot, on pain of regress, be added to (or included in) one of the elements to be combined to justify it. Therefore instrumentalism cannot be supported. From this, it does not follow that we must renounce altogether the normative force of principles of reasoning such as modus ponens ${ }^{10}$ or that there is something wrong with the idea that science education is valuable. Neither should the 'sadness' in the tone of Achilles be interpreted as a legitimate kind of scepticism or a justification of it. Carroll's regress highlights the way that judgement is a necessary characteristic of practice. One has to have learned to judge in a particular way, mastered the art of judgement, to take part in a practice (in such as argumentation), to be able 'to go on'. This also invokes a different concept of practice; that is, an Aristotelian one, but it does so not because instrumental rationality ignores ends, but because even instrumental rationality would not make sense without a context in which one had learned how to apply it. 


\section{Confidence in scholarship and avoiding one sidedness}

When we ask what confidence we can place in educational research, we are drawn to a different set of answers than if we ask what constitutes 'rigorous' or 'excellent' educational research. These shibboleths draw us back into the modernist, scientific - and systematic - way of thinking. The former question, however, tends to release us from the debilitating assumption that the latter is the single legitimate form of thinking, or indeed that there is just any one, hegemonic, kind of educational research. It permits us to see that we can have confidence in ways of thinking, interpreting and researching that are quite different from the (supposedly) scientific. Attention should be given to research that accepts it creates reality, that works with the unstable and that problematizes our knowledge of reality. Consider for example how certain ideals of education as something that has no end beyond education, the ideal of education 'for itself' have been discussed and speak to different generations and kinds of people and how different this is from showing that education is good for something else. It is remarkable how much educational research depicts schools as in principle relatively stable (or stabilisable) places, to be made still more effective, still more highly reliable organizations, as a result of further research, naturally.

The temptation to (wilfully) neglect the above reminders can easily be observed not only in educational research but also in work in the area of philosophy and education. It is not impossible, but it is demanding, not to overstate one's position. After so much hard work, it is understandable if one has an eye only for what one was impressed by and has focused on, or blows things out of proportion, forgetting the need for balance and thus preaches rather than argues, striving to settle things for once and all. Yet the tension between achieving a much-needed sense of order (and other possible orders) cannot be relinquished without paying a price: either to exclude other valuable viewpoints and/or to stop what is nevertheless in motion. It has not gone unnoticed that certain positions focus almost exclusively on a single dimension, for example on what needs to be done, or on the epistemological or the ethical, paying lip-service, or not even that, to the importance of other dimensions, the aesthetical, the religious, the metaphysical. This can work for the sake of the argument when focusing on a particular problem, but this can never be truthful to the nature of what is involved in something so complex as child rearing and education. Resulting in dangerous simplification, it carries the danger of making philosophical discussions superfluous (or even worse, in German Spielerei), a game for insiders familiar with the jargon. This is far away from the serious, balanced reflection that exercises a kind of compulsion, changes the reflective agent and possibly passes on a kind of practical wisdom.

Often, of course, this involves joining others in dialogue where positions are critically, yet respectfully, scrutinized, ${ }^{11}$ reminiscent of the famous saying that a philosopher who does not take part in discussions is like a boxer who never goes into the ring. The order one has imposed on 'the world' may give way to what one is impressed by, created by others who have 'found' meaning and may inspire us to revise our concepts, justifications and stances, in other words how we deal responsibly with what we are 'presented' with. What matters in educational research and in philosophy of education is asking the right kind of questions, which means following Aristotle, looking for precision just as far as the nature of the subject admits. And whether it will lead to finding our place within the world and helping us to make sense of life, there is no alternative when striving to act responsibly.

\section{Funding}

The author received no financial support for the research, authorship, and/or publication of this article. 


\section{Declaration of Conflicting Interest}

The author declares that there is no conflict of interest.

\section{ORCID iD}

Paul Smeyers (iD https://orcid.org/0000-0001-5427-8014

\section{Notes}

1. For more detailed argument concerning 'practices' see for example my introductory chapter in Smeyers, 2018 - more references are given on p. 4, note 5 .

2. The focus here is first of all on content; for method - either in empirical research or in philosophy - see further and endnote 9 .

3. I argued that the promise of neurophilia may be just another neuromyth, which needs to be addressed by philosophy and education - see Smeyers, 2016. Other examples that I discuss elsewhere include 'The Tractarian template in the representation of educational research: Can we ever depart from the picture of logical empiricism' (chapter 7 of Smeyers and Depaepe, 2014) or 'The relevance of irrelevant research; the irrelevance of relevant research' (chapter 6 of Smeyers and Depaepe, 2006).

4. The argument developed here is part of the general critique of evidence-based educational research as developed by authors such as Richard Pring, Richard Smith, Paul Standish, David Bridges and many others. Interesting examples of this line of argument can be found in Bridges, 2017.

5. For a more detailed argument see Smeyers and Smith, 2014, chapter 3.

6. For more detail see, for example, the introductory chapters of Smeyers et al., 2015.

7. This and the following section are partly based on previous collaborative work: Burbules, Bridges, Griffiths and Smeyers, 2015 and Smeyers and Smith, 2014.

8. In the sense that a particular method is prioritized over others.

9. Peter Winch discusses Lewis Carroll's What the Tortoise Said to Achilles. This discussion occupies a central place in The Idea of a Social Science. Winch argues that: 'a form of human activity can never be summed up in a set of explicit precepts. The activity "goes beyond" the precepts. For instance, the precepts have to be applied in practice and, although we may formulate another, higher-order, set of precepts prescribing how the first set is to be applied, we cannot go further along this road without finding ourselves on the slippery slope pointed out by Lewis Carroll in his paper, justly celebrated amongst logicians, What the Tortoise Said to Achilles. . . The moral of this, if we may be boring enough to point it, is that the actual process of drawing an inference, which is after all at the heart of logic, is something which cannot be represented as a logical formula; that, moreover, a sufficient justification for inferring a conclusion from a set of premises is to see that the conclusion does in fact follow. To insist on any further justification is not to be extra cautious; it is to display a misunderstanding of what inference is. Learning to infer is not just a matter of being taught about explicit logical relations between propositions; it is learning to do something'. (Winch, 1958: 55-57)

10. Modus ponens is an argument that takes the form, 'if $p$ then $q$; and $p$, so $q$ '.

11. Examples of what philosophy and philosophy of education can do for education are developed in Smeyers and Smith, 2014. Dealing with parenting and government intervention in the family (chapter 10 ) it is argued that many relevant aspects remain unnoticed in other approaches. The argument of that book is that philosophy not only counts as research but also makes a vital and necessary contribution to understanding the educational field.

\section{References}

Blake N, Smeyers P, Smith R, et al. (eds) (2003) The Blackwell Guide to the Philosophy of Education. Oxford: Blackwell.

Bridges D (2017) Philosophy in Educational Research. Epistemology, Ethics, Policy, and Quality. Dordrecht: Springer.

Burbules N, Bridges D, Griffiths M, et al. (2015) Varieties of interpretation in educational research: How we frame the project. In: P Smeyers, D Bridges, N Burbules and M Griffiths (eds), International Handbook of Interpretation in Educational Research. Dordrecht: Springer, pp.3-16. 
Gibson J and Huemer W (eds) (2004) The Literary Wittgenstein. London: Routledge.

Smeyers P and Depaepe M (eds) (2006) Educational Research: Why 'What Works' Doesn't Work. Dordrecht: Springer.

Smeyers P and Depaepe M (2014) (eds) Educational Research: Material Culture and the Representation of Educational Research. Dordrecht: Springer.

Smeyers P and Smith R (2014) Understanding Education and Educational Research. Cambridge: Cambridge University Press, UK.

Smeyers P, Bridges D, Burbules N, et al. (eds) (2015) International Handbook of Interpretation in Educational Research. Dordrecht: Springer.

Smeyers P (2016) Neurophilia: Guiding educational research and the educational field. Journal of Philosophy of Education 50: 62-75.

Smeyers P (ed.) (2018) International Handbook of Philosophy of Education (2 vols.). Dordrecht: Springer.

Winch P (1958) The Idea of a Social Science and its Relation to Philosophy. London: Routledge.

Wittgenstein L (1953) Philosophical Investigations/Philosophische Untersuchungen (G.E.M. Anscombe, Trans.). Oxford: Basil Blackwell.

Wittgenstein L (1969) The Blue and Brown Books. Oxford: Blackwell.

Wittgenstein L (1980) Culture and Value/Vermischte Bemerkungen (GH von Wright, ed., P Winch, Trans.) Oxford: Basil Blackwell.

\section{Author biography}

Paul Smeyers is since October 2018 emeritus professor (KU Leuven). He taught at KU Leuven and Ghent University (both in Belgium) philosophy of education and methodology of the Geisteswissenschaften (Qualitative/Interpretative Research Methods). He is the author of numerous articles focusing on Wittgenstein's relevance for philosophy of education, on postmodernism, and on issues of the methodology of educational research. He was President of the International Network of Philosophers of Education (20122018) and link-convenor for Network 13, Philosophy of Education (2010-2018), European Educational Research Association. He is since 2014 the Editor of Ethics and Education (Taylor and Francis). Together with Nigel Blake, Richard Smith, and Paul Standish he co-authored three books, Thinking Again, Education in an Age of Nihilism, and The Therapy of Education; with Michael Peters and Nick Burbules Showing and Doing; and with Richard Smith, Making sense of education and educational research (Cambridge University Press, 2014). With Marc Depaepe he co-edited the series Educational Research (Springer, 12 books) and with David Bridges, Morwenna Griffiths, and Nick Burbules he co-edited the International handbook of interpretation in educational research methods (2 vols., Springer, 2015). Recently he edited the International handbook of philosophy of education (2 vols., Springer, 2018). His latest work focuses anew on Wittgenstein's legacy for philosophy of education. Some of that is included in the collection edited by Michael Peters and Jeff Stickney (A Companion to Wittgenstein on Education. Springer, 2017). Attention to Smeyers' contributions in this area are discussed in the Foreword (David Bakhurst), the introductory chapter (Editors), and in a separate chapter by Paul Standish. 